\title{
Acute Effects of 3,4-Methylenedioxymethamphetamine (MDMA) on Behavioral Measures of Impulsivity: Alone and in Combination with Alcohol
}

\author{
Johannes G Ramaekers*,I and Kim PC Kuypers' \\ 'Experimental Psychopharmacology Unit, Department of Neurocognition, Faculty of Psychology, Maastricht University, Maastricht, \\ The Netherlands
}

\begin{abstract}
The use of 3,4-methylenedioxymethamphetamine (MDMA) has frequently been associated with increased levels of impulsivity during abstinence. The effects of MDMA on measures of impulsivity, however, have not yet been studied during intoxication. The present study was designed to assess the acute effects of MDMA and alcohol, alone and in combination, on behavioral measures of impulsivity and risktaking behavior. A total of 18 recreational users of MDMA entered a double-blind placebo-controlled six-way crossover study. The treatments consisted of MDMA 0, 75, and $100 \mathrm{mg}$ with and without alcohol. Alcohol dosing was designed to achieve a peak blood alcohol concentration (BAC) of about $0.06 \mathrm{~g} / \mathrm{dl}$ during laboratory testing. Laboratory tests of impulsivity were conducted between 1.5 and $2 \mathrm{~h}$ post-MDMA and included a stop-signal task, a go/no-go task, and the lowa gambling task. MDMA decreased stop reaction time in the stop-signal task indicating increased impulse control. Alcohol increased the proportion of commission errors in the stop-signal task and the go/no-go task. Signal detection analyses of alcohol-induced commission errors indicated that this effect may reflect impairment of perceptual or attentive processing rather than an increase of motor impulsivity per se. Performance in the lowa gambling task was not affected by MDMA and alcohol, but there was a nonsignificant tendency towards improvement following alcohol intake. None of the behavioral measures of impulsivity showed a MDMA $\times$ alcohol interaction effect. The lack of interaction indicated that the CNS stimulant effects of MDMA were never sufficient to overcome alcohol-induced impairment of impulse control or risk-taking behavior. Neuropsychopharmacology (2006) 31, 1048-1055. doi:I 0. I038/sj.npp. I 300894; published online 14 September 2005
\end{abstract}

Keywords: MDMA; alcohol; interaction; impulsivity; risk taking; acute

\section{INTRODUCTION}

3,4-Methylenedioxymethamphetamine (MDMA) is frequently used in combination with psychoactive drugs. Surveys in Australia (Topp et al, 1999) and Spain (Gamella et al, 1997) have indicated that $40-60 \%$ of MDMA users consumed alcohol concomitantly. Theories of drug use have proposed links with risk-taking behavior and impulsivity particularly among polydrug users (de Wit et al, 2002). Studies that have examined the effect of MDMA on impulsivity in abstinent MDMA users have provided conflicting results. McCann et al (1994) reported a decrement in impulsivity ratings of MDMA users as measured by the Multidimensional Personality Question-

*Correspondence: Dr JG Ramaekers, Experimental Psychopharmacology Unit, Department of Neurocognition, Faculty of Psychology, Maastricht University, Brain and Behavior Institute, PO Box 616, 6200 MD Maastricht, The Netherlands, Tel: + 3I 43 388।95I, Fax: + 31 43 3884125, E-mail: j.ramaekers@psychology.unimaas.nl

Received 5 April 2005; revised 2 August 2005; accepted 5 August 2005 Online publication: 9 August 2005 at http://www.acnp.org/citations/ Npp080905050222/default.pdf naire, whereas others reported elevated scores of impulsivity in heavy MDMA users, using different subjective measures of impulsivity (Butler and Montgomery, 2004; Morgan, 1998, 2000; Parrott, 2000). Elevated levels of impulsiveness have been associated with lower levels of 5HT and CSF-5HIA (Linnoila et al, 1983, 1993) and with dopaminergic activation in the prefrontal cortex leading to a reduction in 'inhibitory control' over behavioral functions (Jentsch and Taylor, 1999). MDMA-induced impulsivity could be accounted for by both mechanisms. Low CSF5HIAA levels have been observed in abstinent and recent MDMA users, whereas dopaminergic turnover is temporarily elevated during MDMA intoxication (Green et al, 2004; Nash, 1990).

Research on MDMA-related impulsivity has generally relied on subjective questionnaires and self-report, which have provided valuable information about impulsivity as a trait in abstinent MDMA users. It has been argued, however, that these measures may not be very well suited for pharmacological studies of impulsivity because they are subjective, measure a relatively stable characteristic, and cannot be directly related to biological models of impulsi- 
vity (Swann et al, 2002). These problems have been overcome by using behavioral measures of impulsivity as defined by the inability to anticipate and reflect on the consequences of decision making or by the failure to inhibit a response in a rapid response task (Bechara et al, 2000; Logan et al, 1984). Studies in MDMA research employing behavioral tests have been relatively sparse but those that were conducted seem to support subjective reports of enhanced impulsivity. Heavy MDMA users produced more commission errors in a go/no-go task (Moeller et al, 2002) and made more risky choices in a gambling task (Butler and Montgomery, 2004) when compared to nondrug users. In addition, current and former MDMA users produced faster responses and more incorrect choices in a matching familiar figures test designed to measure reflection-impulsiveness (Morgan, 1998).

Yet, despite mounting evidence that inhibitory control may be impaired in abstinent MDMA users, the discussion as to its underlying cause remains controversial. A number of confounding factors have been suggested that may account for increments in risk taking or impulsivity observed in MDMA users, besides or instead of MDMA use per se. For example, MDMA users are generally polydrug users of a range of recreational drugs, which makes attribution of impulsivity to either one drug virtually impossible. In addition, it cannot be excluded that impulse and risk-taking behaviors are related to pre-existing low levels of serotonin in MDMA users or that a predisposition to elevated impulsivity underlies the use of MDMA or selfreports and laboratory results from studies in abstinent MDMA users (Butler and Montgomery, 2004; Cole and Sumnall, 2003). Consequently, a better approach for determining a causal relation between MDMA use and change in impulse control may be to conduct placebocontrolled studies on the acute effects of MDMA on laboratory measures of impulse control. Acute studies will be crucial for showing a direct pharmacological link between MDMA use and impulse control during intoxication and may even provide a mechanistic blueprint for MDMA-induced long-term changes in impulse control.

The aim of the present study is to assess the acute effect of MDMA alone and in combination with alcohol on impulsivity in a double-blind placebo-controlled withinsubject design. Impulsivity was either defined as the failure to inhibit a response in rapid response model (go/no-go task and stop-signal task) or as the inability to anticipate and reflect on the consequences of a decision (Iowa gambling task). It was predicted that a general increase in brain 5HT following a single dose of MDMA would improve impulse control. Alcohol has been previously shown to decrease impulse control in rapid response tasks (de Wit et al, 2000; Fillmore and Vogel-Sprott, 1997, 1999) and was included in the present study design as an active control and to assess potential MDMA by alcohol interaction effects.

\section{METHODS}

\section{Subjects}

A total of 18 recreational MDMA users (nine males and nine females) aged 20-37 years were recruited through adver- tisements in local newspapers. All subjects were light-tomoderate users of MDMA who reported to have taken the drug on 2-25 occasions (mean: 9 occasions) in the previous year. Overall, subjects reported to have taken between 2 and 120 MDMA tablets (mean: 18 tablets) in the previous year. Initial screening was accomplished on the basis of a questionnaire on medical history. Subjects who were accepted were examined by the medical supervisor, who also checked vitals signs and took blood and urine samples. Standard blood chemistry, hematological and drug screen tests were conducted on these samples. Inclusion criteria were: experience with the use of MDMA; free from psychotropic medication; good physical health as determined by examination and laboratory analysis; absence of any major medical, endocrine, and neurological condition; normal weight, body mass index (weight/length ${ }^{2}$ ) between 18 and $28 \mathrm{~kg} / \mathrm{m}^{2}$; and written informed consent. Exclusion criteria were: history of drug abuse (other than the use of MDMA) or addiction; pregnancy or lactation; cardiovascular abnormalities as assessed by standard 12-lead ECG; excessive drinking ( $>20$ standard alcoholic consumptions a week); hypertension (diastolic $>100 \mathrm{mmHg}$; systolic $>170 \mathrm{mmHg}$ ); and history of psychiatric or neurological disorder.

This study was conducted according to the code of ethics on human experimentation established by the declaration of Helsinki (1964) and amended in Edinburgh (2000). All subjects gave their informed consent, in writing. Approval for the study was obtained from the University's Medical Ethics committee. A permit for obtaining, storing, and administering MDMA was obtained from the Dutch drug enforcement administration.

\section{Design, Doses, and Administration}

The study followed a double-blind placebo-controlled sixway crossover design. Complete balancing of the treatment orders yielded six treatment orders randomly assigned to 18 subjects. The treatments consisted of MDMA 0,75, and $100 \mathrm{mg}$ with and without alcohol. MDMA and MDMA placebo were administered orally in identically appearing formulations. MDMA was administered as a $25 \mathrm{ml}$ solution in bitter orange peel syrup, which was ingested at once. Alcohol dosing was designed to achieve a peak BAC of about $0.06 \mathrm{~g} / \mathrm{dl}$ during laboratory testing. Alcohol doses were administered at $45 \mathrm{~min}$ post drug, and consumed within a period of $15 \mathrm{~min}$. Subjects' BAC was monitored regularly at $15 \mathrm{~min}$ intervals for 30-90 min after cessation of drinking using a Lion SD-4 Breath Alcohol Analyzer. The minimum wash-out period between successive treatments was 1 week. Laboratory tests were conducted between 1.5 and $2 \mathrm{~h}$ post drug (ie $0.5-1 \mathrm{~h}$ post alcohol).

\section{Procedures}

Subjects were asked to refrain from any drugs starting 1 week before the medical screening and physical examination until 2 weeks after the last experimental session. The subjects were not allowed to use alcohol on the day prior to an experimental session and were requested to arrive at experimental sessions well rested. Drug and alcohol screens in breath and urine were performed prior to experimental 
sessions upon arrival of the subject. Drugs and placebo were only administered in case a subject had passed the urine drug screen on a given test day. Three subjects tested positive for cannabis in urine prior to drug or placebo administration. These subjects were all sent home to return to our laboratory at a later time. Subjects were transported from their homes to the laboratory or vice versa by one of the experimenters in order to prevent subjects from driving under the influence on the day of testing. Additional clinical blood chemistry, with particular reference to liver and renal function was conducted at day 7 after each treatment. All subjects received a training session prior to onset of the experimental sessions in order to familiarize them with the tests and procedures.

\section{Behavioral Tests of Impulsivity}

Stop-signal task. This task requires subjects to make quick key responses to visually presented go signals and to inhibit any response when a visual stop signal is suddenly presented. The current test is adapted from an earlier version of Fillmore et al (2002). The go signals are four $1.5 \mathrm{~cm}$ letters $(\mathrm{ABCD})$ presented one at a time in the center of a computer screen. Subjects are required to respond to each letter as quickly as possible by pressing one of two response buttons. One button is pressed to indicate that ' $A$ ' or ' $C$ ' appeared and the other to indicate ' $B$ ' or ' $D$ '. Letters are displayed for $500 \mathrm{~ms}$ and the computer screen is blank for $1.5 \mathrm{~s}$ interstimulus interval before the next letter is displayed. This provides a period of $2 \mathrm{~s}$ in which the subject can respond to a letter.

A single test consists of 176 trials in which each of the four-letter stimuli is presented equally, often. A stop signal occurred in 48 trials during a test. The stop signal consists of visual cue, ie ' $x$ ' that appears in one of the four corners of the screen. Subjects are required to withhold any response in case a stop signal is presented. Stop signals are presented 12 times at each of the four delays after the onset of a letter: $50,150,250$, and $350 \mathrm{~ms}$. Trials always begin with a $500 \mathrm{~ms}$ preparation interval in which a fixation point appears at the center of the screen. The task lasts for about $10 \mathrm{~min}$. Dependent variables are the proportion of commission errors on stop trials and the reaction times (RT) on go and stop-signal trials (ie stop reaction time). Stop reaction time to stop-signal trials represents the estimated mean time required to inhibit a response.

The method for calculating stop reaction time was taken from the race model of inhibitory control (Logan, 1994). This model proposes that the response to stop-signal trials is defined by two parallel processes: execution of a motor action in response to a signal and inhibition of a motor action in response to stop signal. Crucial to the outcome of the race is the speed of both processes. Response inhibition will fail if the time required to inhibit exceeds the time to complete a motor response at the time of the stop signal. The speed of the inhibition response cannot be observed directly but can be derived mathematically on the basis of three factors: stop-signal delay, reaction time distribution on go trials, and the probability of successful response inhibitions in stop-signal trials. First, RT to 128 go trials were rank ordered from shortest to longest. The finishing time of the inhibition response was then determined from the probability of successful response inhibition and the distribution of RT. If $n \%$ of the responses on stop-signal trials would be unsuccessfully inhibited (ie commission error), than the finishing time would be associated with the $n$th percentile of the RT distribution. Stop reaction time was then determined by subtracting the appropriate stop-signal delay from reaction time at the $n$th percentile of the RT distribution. The resulting values for each stop-signal delay were then averaged to yield a single measure of stop reaction time for the test.

Go/no-go task. The go/no-go task provides a measure of the ability to inhibit or suppress a habit response. During the test, a series of letters (A, E, H, L, K, and X) appear one at a time in the center of the computer screen, and participants are instructed to press the spacebar at the appearance of each letter (go condition). However, if the letter ' $\mathrm{X}$ ' is preceded by ' $A$ ', subjects have to inhibit their prepared responses (no-go condition). Dependent variables include average RT on go trials and errors of commission; that is, pushing the spacebar during no-go trials. In addition, the signal detection theory model (Green and Swets, 1966) was applied to assess the subjects' operation characteristics during task performance. Hit rate $(H$, probability of response inhibition on no-go trials) and false alarm rate ( $F A$, probability of response inhibition on go trials) were established to determine the main parameters of the signal detection model; that is, sensitivity $\left(d^{\prime}\right)$ and response criterion $(\beta)$. Hit and false alarm rates were referred to standardized normal distributions in order to yield $z(H)$ and $z(F A)$. The sensitivity index $d^{\prime}$ is given by $z(H)-z(F A)$ expressed in normal deviates. The response criterion $\beta$ is conceptualized as $f(H) / f(F A)$, where $f(H)$ and $f(F A)$ are the ordinates of the normal curve corresponding to $H$ and $F A$. Sensitivity reflects the discriminability of go trials from no-go trials, whereas the response criterion indicates the minimum level of certainty that is necessary for the subject to make a 'no-go' decision. Two respondents may differ considerably in their criterion, even when they are equally sensitive. A subject's response criterion may be liberal or risky, thereby detecting most of the no-go signals at the cost of many false alarms, or it may be conservative, leading to few false alarms while reducing the probability of detecting no-go signals.

The Iowa gambling task. The subject sees four decks of cards on a computer screen labeled A, B, C, and D at the top end of each deck. With a mouse, the subject can click on a card on any of the four decks. Each deck of cards is programmed to have 40 cards. The gains and losses for each card selection are set so that in each block of 10 cards from deck A or deck B, over the course of trials, there is a total gain of $\$ 1000$ (interspersed with unpredictable losses totalling \$1250). For decks C and D, the gains and losses for each card selection are set so that in each block of 10 cards there is a total gain of $\$ 500$, interrupted by losses totaling \$250 (gains and losses all refer to virtual money). Thus decks A and B are 'disadvantageous' in the long term, while decks C and D are 'advantageous' in the long term. The majority of normal people choose advantageously on this task (ie select more cards from the advantageous relative to the disadvantageous decks). Patients with frontal 
lobe lesions do the opposite, that is, select more disadvantageous cards. The sensitivity, reliability, and validity of this task in detecting decision-making impairments has been tested in neurological as well as psychiatric populations. Thus there is one dependent measure that we collect from this task: net score (total no. of cards picked from C and D minus total no. of cards picked from A and B). Parallel versions of the gambling task are used over six treatment sessions (Bechara et al, 2000, 2001).

\section{Pharmacokinetic Assessments}

MDMA was determined in plasma $(15 \mathrm{ml})$ at $1.5 \mathrm{~h}$ post drug. Blood samples were placed on ice immediately, centrifuged later, and frozen at $-80^{\circ} \mathrm{C}$ until analyses for pharmacokinetic assessments. MDMA and MDA concentrations were determined using solid-phase extraction and gas chromatography with mass spectrometric detection with quantification limits of $1 \mathrm{ng} / \mathrm{ml}$, respectively. BAC concentrations were assessed every $15 \mathrm{~min}$ during the first $2 \mathrm{~h}$ after drinking with a Lion SD-4 Breath Alcohol Analyser.

\section{Statistics}

Data were analyzed by means of repeated measures MANOVA with alcohol (two levels) and MDMA (three levels) and their interaction as main factors. Separate drugplacebo contrasts were conducted following an overall effect of MDMA or the interaction between MDMA and alcohol. The alpha criterion level of significance was set at $p=0.05$.

\section{RESULTS}

Complete data sets $(N=18)$ were collected for the Iowa gambling task and the go/no-go task. In case of the stopsignal task, incomplete data sets were recorded from one subject due to technical problems. Only complete data sets entered the statistical analyses.

Mean (+SE) values recorded in the laboratory tests of impulsivity during every treatment condition and a summary of the statistical analyses are shown in Table 1.

On the stop-signal task, MANOVA indicated a significant overall effect of MDMA on stop reaction time $\left(\mathrm{F}_{2,15}=4.62\right.$; $p=0.027)$. In general, MDMA decreased stop reaction time as compared to placebo treatments. Separate drugplacebo contrasts indicated that this effect was particularly noteworthy for MDMA $75 \mathrm{mg}(p=0.008)$. Mean (SE) stop reaction times in every treatment condition are shown in Figure 1.

MANOVA also revealed significant main effects of alcohol on the percentage of commission errors in the stopsignal task $\left(\mathrm{F}_{1,16}=7.06 ; p=0.017\right)$ and the go/no-go task $\left(\mathrm{F}_{1,17}=7.84 ; p=0.012\right)$. During alcohol treatments the proportion of commission errors was significantly higher

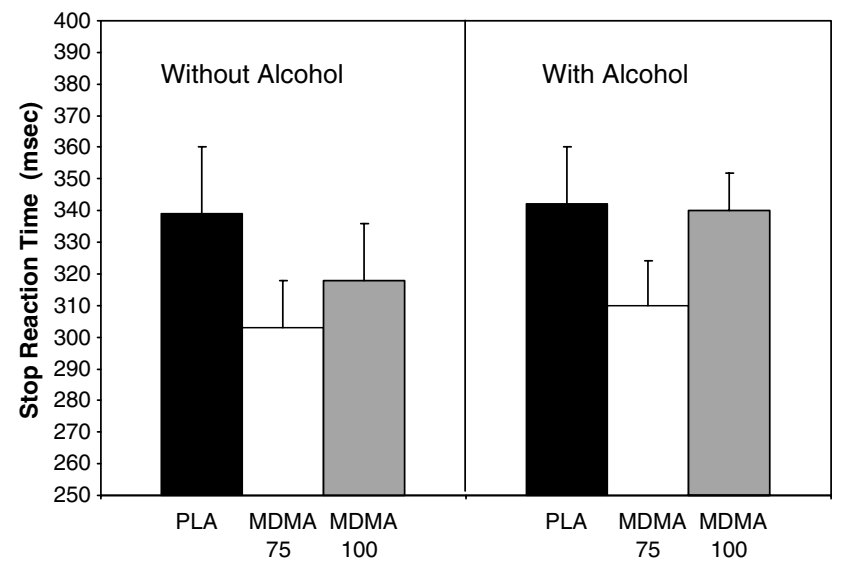

Figure I Mean (SE) stop reaction times in each treatment condition in the stop-signal task.

Table I Mean (SE) Values of all Laboratory Measures of Impulsivity in Every Treatment Condition and a Summary of Significant Treatment Effects of MDMA, Alcohol and their Interaction as Indicated by MANOVA

\begin{tabular}{|c|c|c|c|c|c|c|c|c|c|}
\hline \multirow[b]{2}{*}{ Test } & \multicolumn{3}{|c|}{ Without alcohol } & \multicolumn{3}{|c|}{ With alcohol } & \multicolumn{3}{|c|}{ MANOVA } \\
\hline & PLA & MDMA 75 & MDMA 100 & PLA & MDMA 75 & MDMA 100 & MDMA & ALC & MDMA-by-ALC \\
\hline \multicolumn{10}{|l|}{ Stop-signal task } \\
\hline Stop RT (ms) & $339(21)$ & $303(15)$ & $318(18)$ & $342(18)$ & $310(14)$ & $340(12)$ & 0.027 & - & - \\
\hline Go RT (ms) & $723(60)$ & $648(36)$ & 65। (39) & $658(42)$ & $655(29)$ & $663(37)$ & - & - & - \\
\hline Commission errors (\%) & 17,2(4.6) & I6,7 (4,4) & $19,6(5,1)$ & $23,7(6,1)$ & $16,9(3,4)$ & $21,3(5,1)$ & - & 0.012 & \\
\hline \multicolumn{10}{|l|}{ Go/no-go task } \\
\hline Go RT (ms) & $282(15)$ & $287(16)$ & $294(20)$ & $287(15)$ & $278(14)$ & $288(16)$ & - & - & - \\
\hline Commission errors (\%) & $16,6(2,7)$ & I 7,0 (2,9) & I5,7 (3,4) & $21.0(3,6)$ & $18,4(3,7)$ & $19,8(2,4)$ & - & 0.013 & - \\
\hline Sensitivity $\left(d^{\prime}\right)$ & $4.0(0.2)$ & $4.1(0.1)$ & $4.2(0.2)$ & $3.7(0.2)$ & $3.9(0.2)$ & $3.8(0.2)$ & - & 0.001 & - \\
\hline Response criterion $(\beta)$ & $3.4(0.2)$ & $3.9(0.2)$ & $3.7(0.2)$ & $3.5(0.3)$ & $3.3(0.3)$ & $3.6(0.3)$ & - & - & - \\
\hline \multicolumn{10}{|l|}{ lowa gambling task } \\
\hline
\end{tabular}



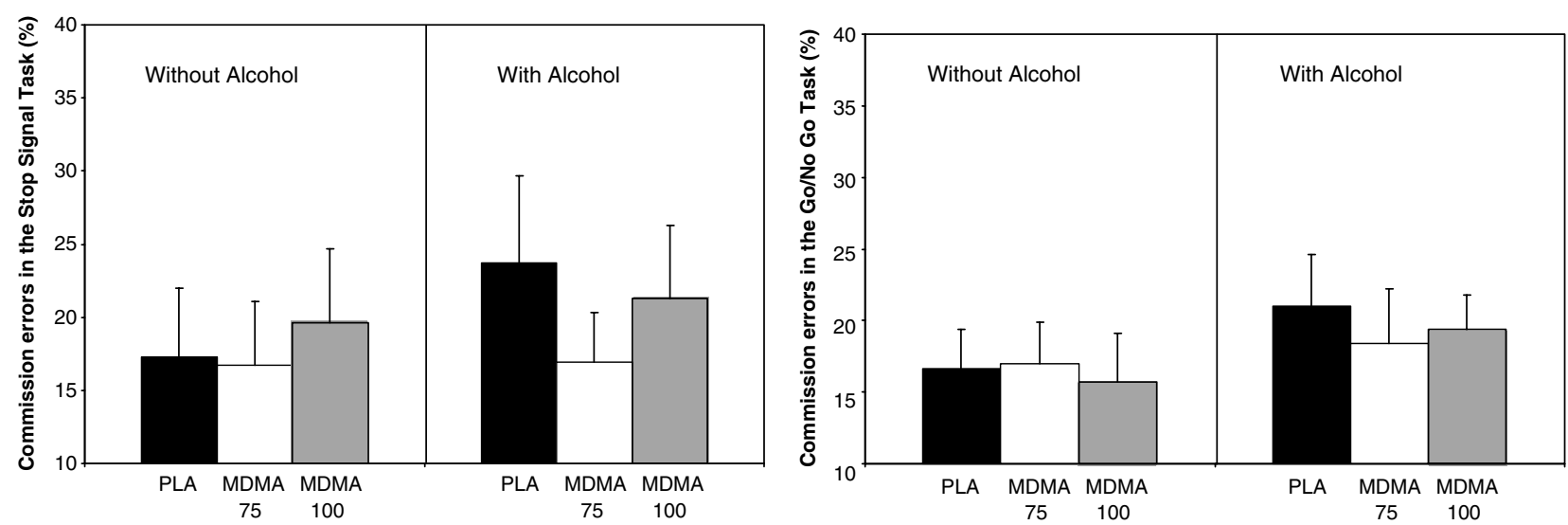

Figure 2 Mean (SE) proportions of commission errors during each treatment condition in the stop-signal task (left panel) and the go/no-go task (right panel).

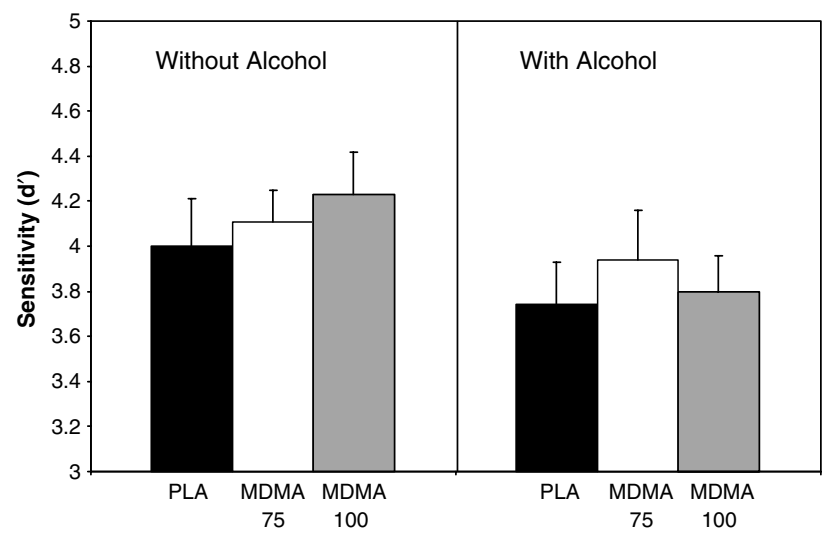

Figure 3 Mean (SE) sensitivity $\left(d^{\prime}\right)$ in each treatment condition in the go/no-go task.

as compared to treatments without alcohol in both tests. Mean proportions of commission errors in all treatment conditions in the stop-signal task and the go/no-go task are shown in Figure 2. Signal detection parameters related to performance at the go/no-go task indicated that the increment in commission errors during alcohol was related to a reduction in the subjects' sensitivity $\left(d^{\prime}\right)$ to distinguish go from no-go signals $\left(\mathrm{F}_{1,17}=18.25 ; p=0.001\right)$, and not to a change in the subjects' response criterion $(\beta)$. Mean (SE) sensitivity in each treatment condition is shown in Figure 3.

In the gambling task, alcohol tended to improve performance as indicated by an almost significant main effect of alcohol $\left(F_{1,17}=3,14 ; p=0.09\right)$. On average, the number of advantageous cards selected during alcohol treatments were higher as compared to treatments without alcohol. MDMA did not affect performance in the gambling task.

There were no alcohol $\times$ MDMA interactions on any behavioral measure of impulsivity.

\section{Pharmacokinetics}

Mean BAC did not significantly differ between treatments. Mean (SE) BACs at the onset of laboratory testing, that is, 30 min post drinking were, respectively, $0.65(0.19), 0.56$ (0.12), and $0.57(0.16) \mathrm{mg} / \mathrm{ml}$, following placebo, MDMA 75 and $100 \mathrm{mg}$. Mean (SE) BACs at the end of laboratory testing, that is, $60 \mathrm{~min}$ post drinking were, respectively, 0.64 (0.16), $0.59(0.11)$ and $0.59(0.12) \mathrm{mg} / \mathrm{ml}$ following placebo, MDMA $75 \mathrm{mg}$ and MDMA $100 \mathrm{mg}$.

MDMA and MDA concentrations were also comparable between treatments. At onset of the laboratory test, that is, $1.5 \mathrm{~h}$ post drug, mean (SE) MDMA concentrations were 137.4 (31.9) and 191.8 (49.1) ng/ml following MDMA 75 and $100 \mathrm{mg}$, respectively. When combined with alcohol, MDMA concentration following the 75 and $100 \mathrm{mg}$ dose were 147 (36.3) and 208.5 (45.7), respectively. MDA concentrations following single doses of MDMA 75, MDMA 100 alone and combined with alcohol were, respectively, 3.5 (1.2), 4.5 (1.5), $3.4(1.0)$, and $4.7(1.4) \mathrm{ng} / \mathrm{ml}$.

\section{DISCUSSION}

The main findings of this study on impulsivity were (1) that acute doses of MDMA improved impulse control in the stop-signal task; (2) that a moderate dose of alcohol impaired the subjects' ability to inhibit responses in the stop signal and go/no-go paradigms; and (3) that MDMA did not affect alcohol-induced impairment in response inhibition tasks.

The present study has been the first to assess the acute effects of MDMA on behavioral measures of impulsivity. In two tasks, ie the stop-signal task and the go/no-go task, impulsivity was defined as the inability to inhibit an activated or pre-cued response leading to errors of commission. In the third task, ie the Iowa gambling task, impulsivity was defined as the inability to anticipate and reflect on the consequences of decision making. In both response inhibition tasks, MDMA did not affect the proportion of commission errors but significantly improved stop reaction time in the stop-signal task. These data indicate that a single dose of MDMA has the potential to stimulate inhibitory motor control in a stop-signal task during intoxication. The pharmacological mechanism underlying improvement in impulse control may be related to acute serotonergic or dopaminergic suppletion following a single dose of MDMA. MDMA is believed to increase 5HT levels during intoxication by stimulating the acute release of $5 \mathrm{HT}$ and by blocking the presynaptic reuptake of $5 \mathrm{HT}$ 
(Steele et al, 1994, 1987). Improved impulse control during serotonergic suppletion seems in line with reports on impaired impulse control in heavy users of MDMA during periods of abstinence. Studies on serotonergic function in recreational MDMA users have repeatedly shown low levels of 5HIAA in CSF (Bolla et al, 1998; McCann et al, 1994; Peroutka et al, 1987; Ricaurte et al, 1990), reduced density of 5-HT transporters (Reneman et al, 2002) and blunted neuro-endocrine responses in serotonergic challenge tests (Gerra et al, 1998; McCann et al, 1999; Verkes et al, 2001) when compared to nondrug using controls. In addition, serotonergic depletion has been linked to behaviors characterized by impaired impulse control (Linnoila et al, $1983,1993)$. Thus, acute improvement of inhibitory control in the stop-signal task following MDMA administration can be interpreted as supportive evidence for current notions on the link between serotonin and impulsivity. Impulsivity levels may drop following serotonin suppletion during acute MDMA intoxication but rise during periods of abstinence when serotonin levels are low.

Alternatively, the reduction in stop reaction time during MDMA intoxication may have also resulted from increased dopaminergic neurotransmission. MDMA is known to also stimulate the release of dopamine and to bind to the presynaptic dopamine reuptake transporters, albeit with less affinity then for the 5HT transporter (Green et al, 2004). Studies on the effects of dopamine agonists on behavioral measures of impulsivity have shown patterns of improvement in impulse control that are similar to the one presented here, following MDMA. D-amphetamine for example, was shown to decrease stop reaction time of healthy volunteers in a stop-signal paradigm without affecting reaction time to go trials (de Wit et al, 2000, 2002). However, opposite effects of amphetamine on behavioral tests of impulsivity have also been found when tested in long-term stimulant abusers. Fillmore et al (2003) reported that an acute dose of d-amphetamine produced a dose-dependent increase in inhibition failures in longterm stimulant abusers performing a cued go/no-go task. Similarly, single doses of cocaine reduced the ability to inhibit responses of cocaine abusers in a stop-signal task (Fillmore et al, 2002). It has been suggested that repeated dopaminergic stimulation of prefrontal pathways leads to impairment of inhibitory functions (Volkow et al, 1997a, b) and that neural changes following chronic stimulant use may alter the behavioral response to acute dopaminergic stimulation (Fillmore et al, 2005). In the present study, the subjects can be best qualified as light-to-moderate MDMA users. Therefore, subject characteristics in the present study would seem more comparable to those in healthy volunteer studies than to those in studies employing long-term drug abusers.

MDMA did not affect measures of impulsivity in every behavioral task employed in the present study. Decisionmaking processes in the Iowa gambling task were not affected by MDMA, which seems to indicate that its effect on stop reaction time in the stop-signal task is rather selective. It has been argued before that impulsivity is a broad conceptual construct that encompasses multiple mechanisms of behavioral control that may be linked to different regions of the brain (Bechara 2004). Two types of impulsivity that can be distinguished are cognitive impulsivity and motor impulsivity. Cognitive impulsivity as measured by the Iowa gambling task is believed to reflect complex processes involved in the control of several cognitive, behavioral and effective processes. More in particular, it assesses the ability to think and reflect on the consequences of a choice prior to making a decision. The ventromedial section in the prefrontal cortex has been indicated as the most critical neural structure underlying these processes (Bechara, 2004; Ridderinkhof et al, 2004). Motor impulsivity or response inhibition as measured in the stop-signal task or go/no-go task, on the other hand, is believed to relate to the control of motor processes that are subserved by the anterior cingulate (Bechara, 2004). Thus, it is entirely possible that a pharmacological manipulation can affect these control systems independently and selectively. The present study thus suggests that MDMA selectively improves control over motor impulsivity, while leaving cognitive impulsivity intact. It is interesting to note that selectivity of MDMA effects have been reported in other psychological domains as well. Lamers et al (2003) demonstrated that a single dose of MDMA produced dissociable effects on psychomotor skills and attention.

The effects of alcohol on measures of behavioral impulsivity were intriguing. Alcohol reduced performance in the stop-signal and go/no-go tasks but almost significantly improved performance in the Iowa gambling task. Similar findings have been reported in the scientific literature. Previous studies employing stop-signal paradigms have reported that alcohol increased stop reaction time (de Wit et al, 2000) or increased the number of commission errors (Fillmore and Vogel-Sprott, 1997, 1999; Mulvihill et al, 1997), suggesting increased impulsivity. Application of signal detection theory to data from the go/ no-go task in the present study indicated that the increase in commission errors during alcohol intoxication did not result from a change in response bias toward more liberal or risky decisions, but from a reduced ability to discriminate go from no-go signals. Or in terms of signal detection parameters: sensitivity $\left(d^{\prime}\right)$ significantly decreased following alcohol treatment, whereas the response criterion $(\beta)$ was unaffected. Sensitivity is a measure of sensory capabilities of the observer or of the effective signal strength, whereas response criterion is a measure of cautiousness and reflects such things as motives and attitudes. The present data thus suggest that the increase in commission errors may reflect impairment of perceptual or attentive processing rather than an increase of motor impulsivity. The absence of an alcohol effect on reaction time in go and no-go trials in the stop-signal task as well as the go/no-go task further supports this notion. It should be noted, however, that overall mean values for sensitivity and response criterion were rather high in the present experiment, which indicates that the go/no-go task was rather easy to perform by the subjects. It would be preferable to increase task difficulty in future studies to further assess the contribution of alcohol-induced changes in sensitivity and response criterion to performance under more compelling laboratory circumstances.

Performance on the Iowa gambling task tended to improve following alcohol treatment but this effect only approached statistical significance. It is still noteworthy, however, since similar effects have been reported in models, 
where cognitive impulsivity is defined as the inability to wait for a larger reward. Ortner et al (2003) employed a delay-discounting task, where healthy volunteers made a series of hypothetical choices between a small, immediate reward and a large, delayed reward. In the alcohol condition, subjects tended to discount delayed reward at lower rates than during the sober condition. This difference was not statistically significant, but suggested that alcohol led to more cautious decision making. Performance stimulating effects were not found by Richards et al (1999) but they did show that alcohol did not detrimentally affect discounting of delayed monetary reward. Although conceptual differences between tasks measuring cognitive impulsivity do exist, it has been shown that performance on delay-discounting tasks is significantly correlated to performance on the Iowa gambling task (Monterosso et al, 2001). Together these results indicate that alcohol does not increase cognitive impulsivity in this type of decisionmaking tasks. The absence of an alcohol effect on decisionmaking tasks $v s$ the presence of a detrimental effect of alcohol on motor inhibition tasks demonstrates once more that impulsivity is not a unitary concept or brain structure but is comprised of several independent psychological domains or brain regions that can respond very selectively to a pharmacological manipulation.

None of the behavioral parameters showed any significant MDMA by alcohol interaction effect. This suggests that MDMA does not alter the effects of alcohol on behavioral measures of impulsivity. This notion seems in line with conclusions from a previous study that assessed combined effects of alcohol and MDMA on psychomotor function during intoxication in humans (Hernandez-Lopez et al, 2002). These investigators reported that MDMA reversed the subjective sedation induced by alcohol but did not change the impairing effect of alcohol on measures of psychomotor function such as simple reaction time and digit symbol substitution. The lack of mitigating effects of MDMA on alcohol-induced impairment on measures of impulsivity or risk tasking may be of particular importance in terms of road safety issues. Most of the MDMA-impaired driving cases that have been reported in the scientific literature consist of drivers who have taken multiple drugs and/or alcohol (Logan and Couper, 2001). The present data indicates that the CNS-stimulating effects of MDMA do not suffice to overcome alcohol-induced impairment of motor control, which is one of the most common causal factors in vehicle crashes.

\section{ACKNOWLEDGEMENTS}

This work was conducted as part of the IMMORTAL research consortium funded by EU Grant GMA1-200027043.

\section{REFERENCES}

Bechara A (2004). Separate neural substrates underlie different mechanisms of performance monitoring and behavioral control. In: Ullsperger M, Falkenstein M (eds). Errors, Conflicts and the Brain. Current Opinions on Performance Monitoring (MPI special issue in human cognitive and brain sciences). Max Planck-Institut fur Kognitions und Neurowissenschaften: Leipzig. pp 55-62.
Bechara A, Damasio H, Damasio AR (2000). Emotion, decision making and the orbitofrontal cortex. Cereb Cortex 10: 295-307.

Bechara A, Dolan S, Denburg N, Hindes A, Anderson SW, Nathan PE (2001). Decision-making deficits, linked to a dysfunctional ventromedial prefrontal cortex, revealed in alcohol and stimulant abusers. Neuropsychologia 39: 376-389.

Bolla KI, McCann UD, Ricaurte GA (1998). Memory impairment in abstinent MDMA ('Ecstasy') users. Neurology 51: 1532-1537.

Butler GK, Montgomery AM (2004). Impulsivity, risk taking and recreational 'ecstasy' (MDMA) use. Drug Alcohol Depend 76: 55-62.

Cole JC, Sumnall HR (2003). Altered states: the clinical effects of Ecstasy. Pharmacol Ther 98: 35-58.

de Wit H, Crean J, Richards JB (2000). Effects of D-amphetamine and ethanol on a measure of behavioral inhibition in humans. Behav Neurosci 114: 830-837.

de Wit H, Enggasser JL, Richards JB (2002). Acute administration of D-amphetamine decreases impulsivity in healthy volunteers. Neuropsychopharmacology 27: 813-825.

Fillmore MT, Kelly TH, Martin CA (2005). Effects of D-amphetamine in human models of information processing and inhibitory control. Drug Alcohol Depend 77: 151-159.

Fillmore MT, Rush CR, Hays L (2002). Acute effects of oral cocaine on inhibitory control of behavior in humans. Drug Alcohol Depend 67: 157-167.

Fillmore MT, Rush CR, Marczinski CA (2003). Effects of Damphetamine on behavioral control in stimulant abusers: the role of prepotent response tendencies. Drug Alcohol Depend 71: 143-152.

Fillmore MT, Vogel-Sprott M (1997). Resistance to cognitive impairment under alcohol: the role of environmental consequences. Exp Clin Psychopharmacol 5: 251-255.

Fillmore MT, Vogel-Sprott M (1999). An alcohol model of impaired inhibitory control and its treatment in humans. Exp Clin Psychopharmacol 7: 49-55.

Gamella JF, Alvarez-Roldan A, Romo N (1997). The content of ecstasy in Spain. In: Korf DJ RH (ed). Proceedings of the 7th Annual Conference on Drug Use and Drug Policy. Siswo: Amsterdam.

Gerra G, Zaimovic A, Giucastro G, Maestri D, Monica C, Sartori R et al (1998). Serotonergic function after (+/-)3,4-methylenedioxymethamphetamine ('Ecstasy') in humans. Int Clin Psychopharmacol 13: 1-9.

Green AR, O'Shea E, Colado MI (2004). A review of the mechanisms involved in the acute MDMA (ecstasy)-induced hyperthermic response. Eur J Pharmacol 500: 3-13.

Green DM, Swets JA (1966). Signal Detection Theory and Psychophysics. Wiley: New York.

Hernandez-Lopez C, Farre M, Roset PN, Menoyo E, Pizarro N, Ortuno J et al (2002). 3,4-Methylenedioxymethamphetamine (ecstasy) and alcohol interactions in humans: psychomotor performance, subjective effects, and pharmacokinetics. J Pharmacol Exp Ther 300: 236-244.

Jentsch JD, Taylor JR (1999). Impulsivity resulting from frontostriatal dysfunction in drug abuse: implications for the control of behavior by reward-related stimuli. Psychopharmacology (Berlin) 146: 373-390.

Lamers CT, Ramaekers JG, Muntjewerff ND, Sikkema KL, Samyn N, Read NL et al (2003). Dissociable effects of a single dose of ecstasy (MDMA) on psychomotor skills and attentional performance. J Psychopharmacol 17: 379-387.

Linnoila M, Virkkunen M, George T, Higley D (1993). Impulse control disorders. Int Clin Psychopharmacol 8(Suppl 1): 53-56.

Linnoila M, Virkkunen M, Scheinin M, Nuutila A, Rimon R, Goodwin FK (1983). Low cerebrospinal fluid 5-hydroxyindoleacetic acid concentration differentiates impulsive from nonimpulsive violent behavior. Life Sci 33: 2609-2614. 
Logan BK, Couper FJ (2001). 3,4-Methylenedioxymethamphetamine (MDMA, ecstasy) and driving impairment. J Forensic Sci 46: $1426-1433$

Logan GD (1994). On the ability to inhibit though and action: a users' guide to the stop signal paradigm. In: Dagenbach D, Carr TH (eds). Inhibitory processes in attention, memory and language. Academic Press: San Diego. pp 189-239.

Logan GD, Cowan WB, Davis KA (1984). On the ability to inhibit simple and choice reaction time responses: a model and a method. J Exp Psychol Hum Percept Perform 10: 276-291.

McCann UD, Eligulashvili V, Mertl M, Murphy DL, Ricaurte GA (1999). Altered neuroendocrine and behavioral responses to $\mathrm{m}$-chlorophenylpiperazine in 3,4-methylenedioxymethamphetamine (MDMA) users. Psychopharmacology (Berlin) 147: 56-65.

McCann UD, Ridenour A, Shaham Y, Ricaurte GA (1994). Serotonin neurotoxicity after $(+/-) 3,4$-methylenedioxymethamphetamine (MDMA; 'Ecstasy'): a controlled study in humans. Neuropsychopharmacology 10: 129-138.

Moeller FG, Dougherty DM, Steinberg JL, Swann AC, Silverman PB, Kramer LA et al (2002). Heavy 'ecstasy' use is associated with increased impulsivity. Addict Disord Treatment 1: 47-52.

Monterosso J, Ehrman R, Napier KL, O’Brien CP, Childress AR (2001). Three decision-making tasks in cocaine-dependent patients: do they measure the same construct? Addiction 96: $1825-1838$.

Morgan MJ (1998). Recreational use of 'ecstasy' (MDMA) is associated with elevated impulsivity. Neuropsychopharmacology 19: $252-264$.

Morgan MJ (2000). Ecstasy (MDMA): a review of its possible persistent psychological effects. Psychopharmacology (Berlin) 152: $230-248$.

Mulvihill LE, Skilling TA, Vogel-Sprott M (1997). Alcohol and the ability to inhibit behavior in men and women. J Stud Alcohol 58: 600-605.

Nash JF (1990). Ketanserin pretreatment attenuates MDMAinduced dopamine release in the striatum as measured by in vivo microdialysis. Life Sci 47: 2401-2408.

Ortner CN, MacDonald TK, Olmstead MC (2003). Alcohol intoxication reduces impulsivity in the delay-discounting paradigm. Alcohol Alcohol 38: 151-156.

Parrott AC (2000). Human research on MDMA (3,4-methylenedioxymethamphetamine) neurotoxicity: cognitive and behavioural indices of change. Neuropsychobiology 42: 17-24.
Peroutka SJ, Pascoe N, Faull KF (1987). Monoamine metabolites in the cerebrospinal fluid of recreational users of 3,4-methylenedioxymethamphetamine (MDMA, 'ecstasy'). Res Commun Subst Abuse 8: 125-138.

Reneman L, Endert E, de Bruin K, Lavalaye J, Feenstra MG, de Wolff FA et al (2002). The acute and chronic effects of MDMA ('ecstasy') on cortical 5-HT2A receptors in rat and human brain. Neuropsychopharmacology 26: 387-396.

Ricaurte GA, Finnegan KT, Irwin I, Langston JW (1990). Aminergic metabolites in cerebrospinal fluid of humans previously exposed to MDMA: preliminary observations. Ann NY Acad Sci 600: 699-708; discussion 708-710.

Richards JB, Zhang L, Mitchell SH, de Wit H (1999). Delay or probability discounting in a model of impulsive behavior: effect of alcohol. J Exp Anal Behav 71: 121-143.

Ridderinkhof KR, van den Wildenberg WP, Segalowitz SJ, Carter CS (2004). Neurocognitive mechanisms of cognitive control: the role of prefrontal cortex in action selection, response inhibition, performance monitoring, and reward-based learning. Brain Cogn 56: 129-140.

Steele TD, McCann UD, Ricaurte GA (1994). 3,4-Methylenedioxymethamphetamine (MDMA, 'Ecstasy'): pharmacology and toxicology in animals and humans. Addiction 89: 539-551.

Steele TD, Nichols DE, Yim GK (1987). Stereochemical effects of 3,4-methylenedioxymethamphetamine (MDMA) and related amphetamine derivatives on inhibition of uptake of [3H]monoamines into synaptosomes from different regions of rat brain. Biochem Pharmacol 36: 2297-2303.

Swann AC, Bjork JM, Moeller FG, Dougherty DM (2002). Two models of impulsivity: relationship to personality traits and psychopathology. Biol Psychiatry 51: 988-994.

Topp L, Hando J, Dillon P, Roche A, Solowij N (1999). Ecstasy use in Australia: patterns of use and associated harm. Drug Alcohol Depend 55: 105-115.

Verkes RJ, Gijsman HJ, Pieters MS, Schoemaker RC, de Visser S, Kuijpers $\mathrm{M}$ et al (2001). Cognitive performance and serotonergic function in users of ecstasy. Psychopharmacology (Berlin) 153: 196-202.

Volkow ND, Wang GJ, Fowler JS (1997a). Imaging studies of cocaine in the human brain and studies of the cocaine addict. Ann NY Acad Sci 820: 41-54; discussion 54-55.

Volkow ND, Wang GJ, Fowler JS, Logan J, Gatley SJ, Hitzemann R et al (1997b). Decreased striatal dopaminergic responsiveness in detoxified cocaine-dependent subjects. Nature 386: 830-833. 